\title{
Radiocarbon
}

1993

\section{RADIOCARBON AND 11-YEAR VARIATIONS OF COSMIC RAYS}

\author{
A. A. BURCHULADZE, S. V. PAGAVA, G. I. TOGONIDZE and M. V. AVTANDILASHVILI \\ Radiocarbon Laboratory, Tbilisi State University, Chavchavadze 3, Tbilisi 380008 Georgia
}

\section{INTRODUCTION}

B. P. Konstantinov and G. E. Kocharov $(1965,1967)$ addressed the complex problem of astrophysical phenomena and radiocarbon. Currently available data show that the determination of cosmogenic ${ }^{14} \mathrm{C}$ in accurately dated samples of terrestrial and atmospheric origin is one of the most reliable and promising methods for studying cosmic-ray variations in the past. ${ }^{14} \mathrm{C}$ dating samples of terrestrial origin has helped solve the problem of long-term (100 $\mathrm{yr}$ or more) ${ }^{14} \mathrm{C}$ variations and, accordingly, of cosmic-ray variations in the past. Short-term (ca. $11 \mathrm{yr}$ or less) variations are still under investigation (Alexeyev et al. 1971; Damon, Long and Wallick 1973).

Through the agreement on scientific and cultural cooperation between the Universities of Bratislava, Slovakia and Tbilisi, Georgia, this problem was studied by measuring ${ }^{14} \mathrm{C}$ variations in samples of known age (dendrodated tree rings from Slovakia and ethyl alcohols from Georgian wines) from 1909 to 1952. The results are presented in Figures 1 and 2. Short-term ${ }^{14} \mathrm{C}$ variations are difficult to observe in nature. To avoid the possibility of methodological errors, and to ensure reliable results, investigations were performed using different methods for determination of ${ }^{14} \mathrm{C}$ activity. Different biological properties of accurately dated organic objects of terrestrial origin were also considered. The analysis of experimental data shows good concordance of results. The few observed discrepancies do not contradict the general agreement.

\section{RESULTS AND DISCUSSION}

Lines I and II in Figure 1, constructed by the least squares method, represent the dilution rate of natural ${ }^{14} \mathrm{C}$ concentration in the atmosphere resulting from the inflow of $\mathrm{CO}_{2}$ (Burchuladze et al. 1978; Povinec 1975; Dergachev et al. 1974). Line II, used as reference, enables us to exclude both anthropogenically induced and long-term variations from the experimentally observed short-term variations of ${ }^{14} \mathrm{C}$ in the atmosphere. Figure 3 shows short-term variations relative to reference line II. Figure 3 also gives the values of the Wolf number, W, characterizing sunspot activity during the interval of our investigation. This activity, in turn, predetermines cosmic-ray variability.

Hidden periodicities in the stationary ${ }^{14} \mathrm{C}$ series (respectively, in the series of $\mathrm{W}$ numbers) shown in Figure 3 were revealed by spectral analysis (Dorman 1975). Figures 4 and 5 present the results. The sample autocorrelation functions, $r_{1}(u)$ and $r_{2}(u)$, for $\sigma^{14} C(t)$ and $W(t)$, respectively, show a quasi-periodic behavior with the period, $\mathrm{T}_{\mathrm{O}}=11 \pm 1 \mathrm{yr}$, at $95 \%$ confidence interval. Note that in both cases, the spectra of $r_{1,2}(u)$ are very sharp and have a similar shape. The spectral evaluation of $\sigma^{14} \mathrm{C}(\mathrm{t})$ and $\mathrm{W}(\mathrm{t})$ confirms the results of autocorrelation analysis, and shows that the basic power of the spectrum is concentrated on the frequency, $f_{o}=10^{-9} \mathrm{~Hz}$, which corresponds to the period, $\mathrm{T}_{\mathrm{O}}=11 \mathrm{yr}$. Bursts can also be observed at lower frequencies. 

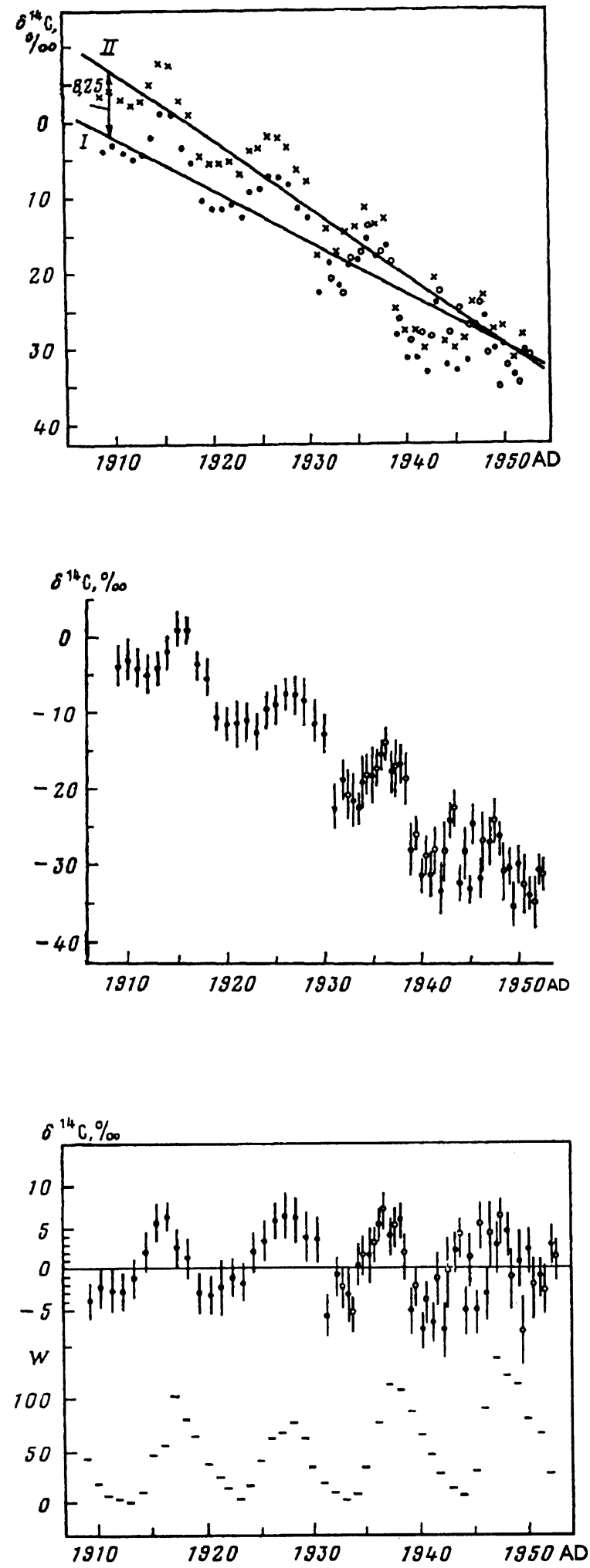

Fig. 1. Variation of the natural ${ }^{14} \mathrm{C}$ concentration in the atmosphere, AD 1909-1952. Line $I$ is constructed by experimental values of $\sigma^{14} \mathrm{C}$ disregarding $\beta$ decay; line II takes $\beta$ decay into account. $\circ=$ Bratislava University; $\bullet=$ Tbilisi University; $x=$ taking radioactive decay into account.

Fig. 2. Same as Fig. 1, but with absolute error values. $\circ=$ results of the investigation of dendrodated tree rings in Slovakia; ${ }^{\bullet}=$ results of analyses of ethyl alcohols synthesized from the dated collection of dry wines of Georgia.

Fig. 3. Variations of ${ }^{14} \mathrm{C}$ in the atmosphere 1909-1952, relative to reference line II (Fig. 1), i.e., relative to natural ${ }^{14} \mathrm{C}$ activity in the atmosphere in $\mathrm{AD} 1960$ 


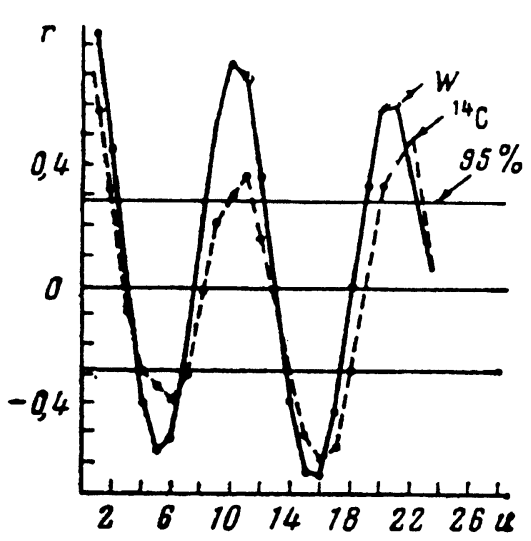

Fig 4. Sample autocorrelation functions, $\mathrm{r}_{1}(\mathrm{u})$ and $r_{2}(u)$, for the $\sigma^{14} \mathrm{C}$ and $W$ series for 1909 to 1952

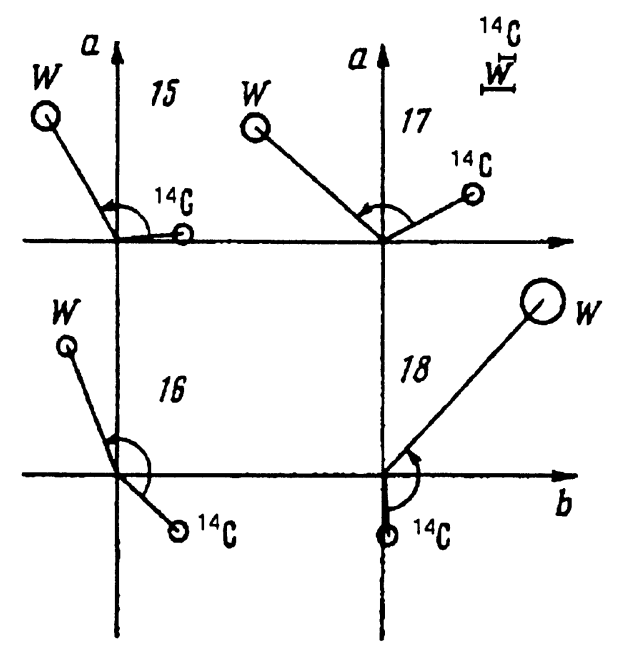

Fig. 6. The harmonic diagram of $11-\mathrm{yr}$ variations in $\sigma^{14} C(t)$ and $W(t)$ 1909-1952 for individual 11-yr cycles

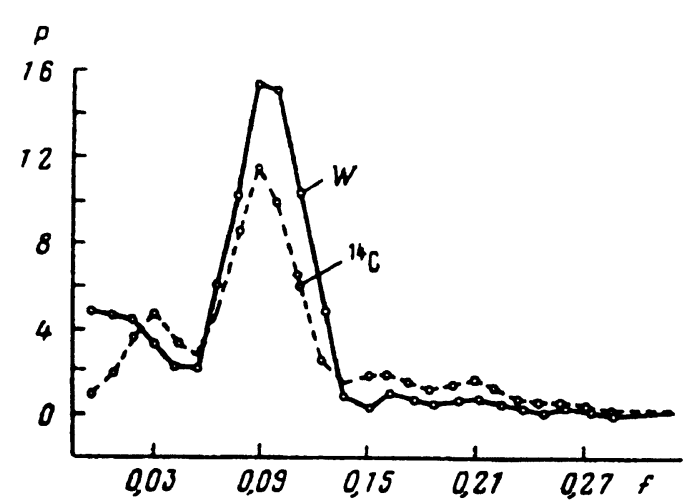

Fig. 5. Sample evaluation of the spectrum for the $\sigma^{14} \mathrm{C}$ and $\mathrm{W}$ series of the investigated time interval

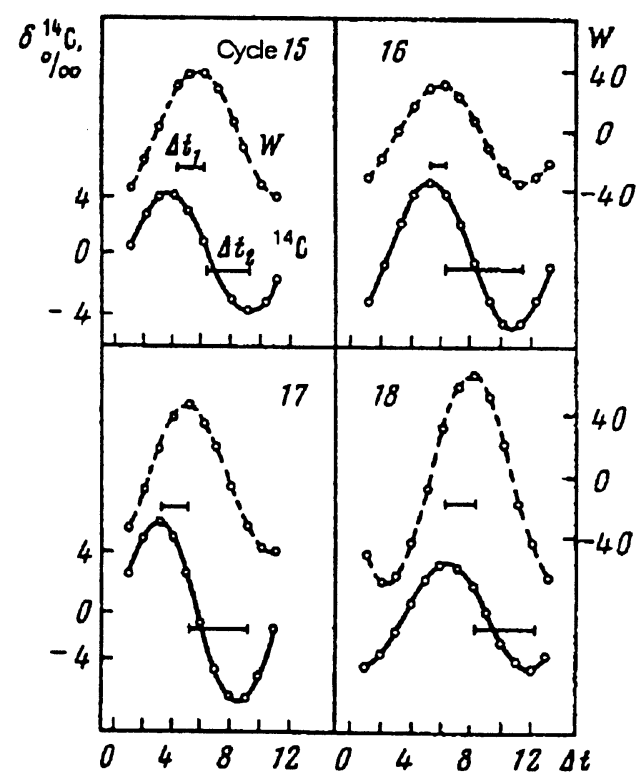

Fig. 7. The first harmonics of the $\sigma^{14} \mathrm{C}(\mathrm{t})$ and $\mathrm{W}(\mathrm{t})$ series for individual 11-yr solar cycles

The results of investigation of short-term variations of ${ }^{14} \mathrm{C}$ on the basis of spectral analysis data were systematized using the harmonic analysis technique described in Dorman (1975). The harmonic analysis of $\sigma^{14} \mathrm{C}(\mathrm{t})$ and $\mathrm{W}(\mathrm{t})$ data enables us to evaluate not only their average variation amplitude in 1909-1952 and variation amplitude during individual 11-yr solar cycles, but also to determine lag times of quasi-periodic ${ }^{14} \mathrm{C}$ variations relative to phenomena occurring on the Sun. Figures 6 and 7 show the harmonic analysis results. As the analysis shows, the average amplitude of ${ }^{14} \mathrm{C}$ variations with an 11-yr period is $\mathrm{r}_{1}=4.7 \pm 0.5 \%$ and, accordingly, the average variation amplitude of $\mathrm{W}$ is $\mathrm{r}_{2}=49.7 \pm 5.0 \%$. 


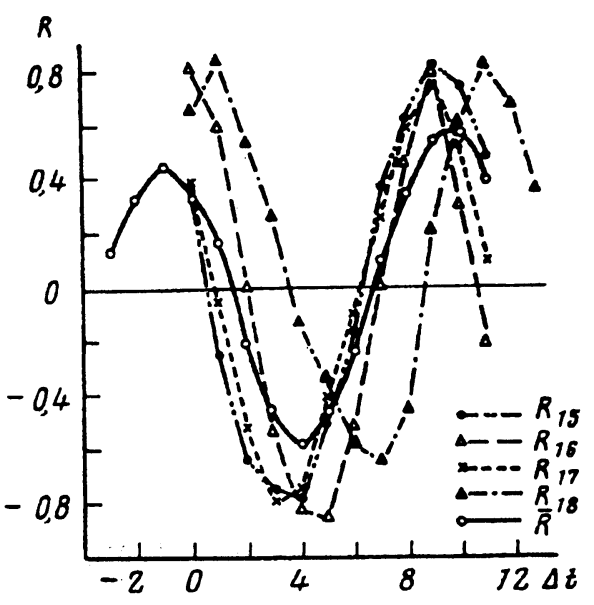

Fig. 8. The correlation coefficients of $\sigma^{14} \mathrm{C}$ and $\mathrm{W}$ with various time shifts.
Besides the harmonic analysis, we calculated the correlation coefficients, $R$, between $\sigma^{14} \mathrm{C}$ and $\mathrm{W}$ with various time shifts, both for full series covering the investigated time interval and for individual 11-yr solar cycles. The results of correlation analysis are presented in Figure 8. The comparison of the results of harmonic and correlation analyses shows that throughout the entire period, 1909-1952, we observe a clearly pronounced anticorrelation dependence with an average time shift of $3.5 \mathrm{yr}$. Note that the anticorrelation dependence is more clearly observed in individual 11-yr solar cycles than in full series.

\section{CONCLUSION}

${ }^{14} \mathrm{C}$ investigations of accurately dated organic samples of terrestrial origin found at various points of the Earth's surface show 11-yr quasi-periodic variations of ${ }^{14} \mathrm{C}$ in nature, with an average amplitude of $4.7 \pm 0.5 \%$. As with 11 -yr variations of galactic cosmic rays, the ${ }^{14} \mathrm{C}$ series of the period $1909-1952$ clearly shows the solar modulation effect and, although bursts of solar cosmic rays are observed during this period as well, they do not affect the essential character of short-term ${ }^{14} \mathrm{C}$ variations.

\section{ACKNOWLEDGMENTS}

The authors express deep gratitude to Professor G. E. Kocharov for his interest in this research and useful discussions of the obtained results. The authors are also obliged to M. Alania for his help in processing experimental data.

\section{REFERENCES}

Alexeyev, V. A., Lavrukhina, A. K. and Milnikova, Z. K. 1971 Radiocarbon variations in sequoia rings. In Collections of Radiocarbon Papers. Vilnius: 45-48.

Baxter, M. S. and Wolton, A. 1971 Fluctuations in atmospheric carbon-14 concentrations during the past century. Philosophical Transactions of the Royal Society, London A 321: 105.

Burchuladze, A. A., Pagava, S. V. and Povinec, P. 1978 Solar activity and short-term radiocarbon variations in the period 1930-1954. Proceedings of Tbilisi State University 203: 32-36.

Damon, P. E., Long, A. and Wallick, E. I. 1973 Comments on "Radiocarbon": Short-term variations by M. S. Baxter and T. G. Farmer. Earth and Planetary Science Letters 20: 311-314.

Dergachev, V. A., Kocharov, G. E., Metskhvarishvili, R. Ya. and Sanadze, A. A. 1974 Proceedings of the 6th Leningrad Seminar on Cosmophysics. Physico-Technical Institute, Leningrad: $178 \mathrm{p}$.

Dergachev, V. A., Kocharov, G. E. and Tleugaliyev, S. Kh., eds. 1977 Proceedings of the 9th Leningrad Seminar on Cosmophysics. Physico-Technical Institute, Leningrad: $361 \mathrm{p}$.
Dorman, L. I. 1975 Experimental and Theoretical Principles of Astrophysics of Cosmic Rays. Moscow, Nauka: 462 p.

Kocharov, G. E., Dergachev, V. A. and Sanadze, A. A., eds. 1974 Proceedings of the 6 th Leningrad Seminar on Cosmophysics. Physico-Technical Institute, Leningrad: $164 \mathrm{p}$.

Konstantinov, B. P. and Kocharov, G. E. 1965 Astrophysical phenomena and radiocarbon. Bulletin of the USSR Academy of Sciences 65: 63-64.

1967 Astrophysical phenomena and radiocarbon. Preprint, Physico-Technical Institute 64. Leningrad. Metskhvarishvili, R. Ya., Imedadze, T. Sh. and Tleugaliyev, S. Kh., eds. 1978 Proceedings of the 9th Leningrad Seminar on Cosmophysics. Physico-Technical Institute, Leningrad: $367 \mathrm{p}$.

Povinec, P. 1975 Isotope generation in the Earth's atmosphere under the action of solar eruption particles. In Proceedings of the 7th Leningrad International Seminar. Physico-Technical Institute, Leningrad: $363-375$. 